\title{
Now and then: Revisiting early childhood teachers' reactions to curriculum change
}

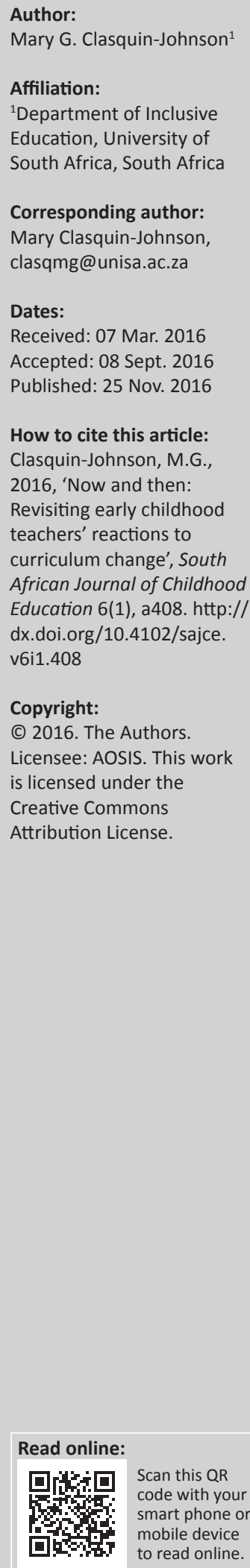

\begin{abstract}
This article reports on the findings of a study consisting of two phases. Both phases aimed at investigating how professional development, physical resources and instructional support influenced teachers' responses to curriculum change. Despite more than $90 \%$ of Grade R teachers being under-qualified, they have had to implement two radically different curricula over the past decade. The initial study ('Phase 1'), conducted in 2007-2010, investigated teachers' responses to the National Curriculum Statement. The 2015 follow-up study ('Phase 2') focused on the same teachers, but the focus fell on the Curriculum and Assessment Policy Statements. The latter occurred in a drastically different context because of the improved monitoring and support systems. A qualitative case study design was employed within an interpretive paradigm. The findings of Phase 1 suggested that the teachers ignored, resisted, adopted and adapted curriculum change. Their highly individualised responses could be attributed to their professional isolation. In contrast, the findings of Phase 2 reveal policy fidelity because of their enhanced capacity to adopt curriculum change. Notably, curriculum implementation is presently occurring within a community of practice. This has the potential to be a catalyst for effecting curriculum change.
\end{abstract}

\section{Introduction}

Mandated curricula have been introduced in early childhood education (ECE) in many countries (Burgess, Robertson \& Patterson 2010; Ebbeck \& Chan 2010; Haug \& Storø, 2015; Logan, Sumsion \& Press 2015; Zhu 2015), including South Africa. This international trend reflects globalisation of education standards to improve outcomes for children and a nation's human capital (Aubrey \& Durmaz 2012:62; Lingarda, Martinob \& Rezai-Rashtib 2013:540; Savage, O'Connor \& Brass 2014:18). Internationally, the focus on a preschool year originates from the United Nations Convention on the Rights of the Child (1989) aimed at preparing children for formal schooling. In South Africa, the reception year (commonly referred to as Grade R) was introduced in 2001 (Department of Education 2001:5) to not only provide a bridging year for school readiness but also address past imbalances, specifically race-based early childhood care and education, and provide equal opportunities (Ebrahim 2010:7,9).

Although access to and quality of Grade R programmes have drastically increased, researchers such as Atmore (2013) have noted the persistence of key challenges, particularly infrastructure, nutrition, teacher professional development, institutional capacity and funding. In addition, van der Berg et al. (2013) have described the impact of Grade R on learning outcomes as 'small' and contend that instead of reducing inequalities, Grade R further extends the advantage of more affluent schools.

In 2004, the official curriculum, the National Curriculum Statement (NCS), was introduced into Grade R programmes. In 2011, the NCS was replaced by the Curriculum and Assessment Policy Statements (CAPS). The implementation of these official curricula was paralleled by the phasedin implementation of Grade R programmes following the release of White Paper No. 5 on Early Childhood Development (Department of Education 2001:5; Janse van Rensburg 2015:107). Despite more than $90 \%$ of Grade R teachers in South African public primary schools being under-qualified (Hoadley 2013:76), they have therefore had to implement two radically different curricula over the past decade.

In the light of the above concerns, the aim of this article is to illustrate how professional development, physical resources and instructional support influence teachers' responses to curriculum change. Brew and Cahir's (2014:341) observation that learning and teaching priorities shift more quickly than the time it takes to implement them, subsequently requiring teachers to change direction midstream in order to respond to new learning and teaching policies before the

Note: This article is a follow-up on the author's PhD thesis: 'Responses of early childhood teachers' to curriculum change in South Africa'. 
previous one is fully understood, let alone embedded, has special relevance to ECE teachers in South Africa. Moreover, curriculum change leads to professional vulnerability and diminishes teachers' self-efficacy and professional well-being (Liyanage et al. 2015:254, 256; Saylor \& Kerkhoff 2014:1).

\section{Understanding teachers' responses to curriculum change}

The literature on policy implementation highlights the role of teachers in any effort to improve instruction and conceptualises the relationship between teachers and curriculum change as a process of fidelity, mutual adaptation or enactment (Ballet \& Kelchtermans 2008). Several studies have examined teachers' responses to curriculum change (Brundrett \& Duncan 2014; Hooghuis, et al. 2014; Lowrie 2014; Rekkor, Ümarik \& Loogma 2013; Ryder 2015). In particular, research has revealed that teachers' responses are shaped by their individual conceptions of teaching and learning, knowledge and skills, and beliefs and interests. Based on his analysis of 40 years of curriculum change, Goodson (2014) contends that contemporary change is invented and originates within external constituencies, consisting of political and commercial interest groups. These groups often overlook teachers' need for a 'sense of purpose and passion' to implement change (Goodson 2014:771). Thus, the key lacuna (or gap) in implementing curriculum change is linking teachers' professional beliefs to their daily practices.

According to Pinar (1999:366), daily educational practice should be understood theoretically. This study utilises the relational theory of change that enhances our understanding of how teachers address multiple voices in their work (Leander \& Osborne 2008:44) when they have to consider the demands made by parents, school principals, colleagues, departmental officials, policy-makers and the public. In short, education is permanently under the political microscope (Burns, Yendol-Hoppey \& Jacobs 2015). I also considered the work of Rowan and Miller (2007:256) who have drawn upon cognitive theories of implementation to understand how teachers make decisions when they interpret and respond to change. Similarly, MacLean et al. (2015:79) and Hökkä and Vähäsantanen (2014:131) are in accord that teacher agency provides an alternative conception of teachers and curriculum, because it involves intellectual engagement and the volitional character of human action (Pinar 1999:366-367).

MacLean et al. (2015:79) as well as Merekua and Merekub (2015:21) cite empirical evidence that the context and process of mandated change often lead to the marginalisation of teachers, especially when it is not rooted in teachers' realities and expertise. According to Ryder (2015:88), this is even more pertinent when curriculum change is externally driven and teachers do not proactively choose to adopt it. As a consequence of curriculum change, teachers doubt their efficacy, and their moral commitment to implementation is undermined. Although teachers do not have a choice between change and non-change (or stability), they do have a choice about how to respond and have considerable discretion as to whether they implement change in their classrooms (Hökkä \& Vähäsantanen 2014:131). For teachers to change their practices, they must believe in the process in which they are engaged (Crump 2005:9).

\section{Conceptual framework matrix on teachers' responses to curriculum change}

I drew on Webster and Watson's (2002:xiv) conceptual model based on a synthesis and extension of existing research to design my conceptual matrix. My aim was to illuminate the complex landscape of curriculum change (Brew \& Cahir 2014; Brundrett \& Duncan 2014; Qiana \& Walker 2013; Ryder 2015) characterised by constant change and overlapping reforms. As a result, teachers who are key agents of curriculum change (Burns et al. 2015; Rekkor et al. 2013), respond to curriculum change in the following ways: they ignore, resist, adopt or adapt the official curriculum (Lindblad 1990; Richardson \& Placier 2002).

Teacher agency in curriculum change can be passive or active. Hökkä and Vähäsantanen (2014:133) and Smylie and Perry (2005:320) regard teachers as active agents when they adapt elements of curriculum change to their classrooms. Crump (2005:2) asserts that teachers need a clear and wellargued reason for change, especially when it comes to the curriculum. Similarly, Goodson (2014:771) highlights teachers' need for a 'sense of purpose and passion' especially when change is externally mandated. If teachers disagree with the need for change, they often respond by resisting (Leander \& Osborne 2008:28). Policy-makers therefore need to be mindful that policy is not so much implemented as it is re-invented at each level of the system (DarlingHammond 2005:363). Bell and Stevenson (2005:20) identify the 'multiplicity of interpretations' as the effect of multiple readers' 'decoding' of policy texts because each reader has his and/or her own context, history and values.

Similarly, policy responses are shaped by wider structural factors that have a cogent effect on individuals' capacity to shape policy. Hooghuis et al. (2014:246) argue that teachers' capacity to implement curriculum change is influenced amongst others by their own pedagogical content knowledge, the education system as well as their school's culture. Teachers therefore rarely simply adopt and implement the curriculum; they have an active relationship with the curriculum and subsequently adapt it to suit their teaching practices (Brundrett \& Duncan 2014:2; Philippou, Kontovourki \& Theodorou 2014:612; Rekkor et al. 2013:490).

In this study, I adopt the notion that curriculum change is highly dependent on teachers' knowledge, skills, beliefs and attitudes. In addition, teachers' responses to curriculum change are influenced by factors external to themselves. The purpose of this study was to explore Grade $\mathrm{R}$ teachers' 
responses to curriculum change at 5-year intervals. Phase 1 was conducted 5 years after the introduction of the NCS, and Phase 2 was conducted 5 years after the introduction of CAPS. This afforded me the opportunity to examine teachers' responses to two different curricula. In both phases, I paid specific attention to the external factors, namely professional development, physical resources and instructional support, that influence Grade $\mathrm{R}$ teachers' responses to curriculum change.

\section{Methodology Approach and justification}

The study followed a qualitative approach, was conducted in two phases and employed a case study design to illuminate how Grade R teachers make operational decisions (Wiersma \& Jurs 2009:241) as they respond to the implementation of the official curricula. Phase 1 was conducted between 2007 and 2010. Phase 2 was conducted during 2015, 5 years later.

\section{Context and participants}

Case selection focused on nine Grade $\mathrm{R}$ teachers located at public primary school-based Grade R programmes in their natural contexts, bounded by time and activity (Creswell 2003:15). Grade R teachers constitute the main unit of analysis because they are considered by most policy-makers and school change experts to be the centrepiece of educational change (Rekkor et al. 2013:492; Qiana \& Walker 2013:305). In Phase 1, care was taken to choose the Grade R teachers from a range of public school settings in Johannesburg and Pretoria (Tshwane). Purposive sampling was used to select nine Grade $\mathrm{R}$ teachers. The study therefore focused on nine teachers, located at four school-based ECE programmes, and each reveals a different perspective on how teachers respond to curriculum change (Creswell 2007:75). The same participants were studied in both phases, although one of the nine participants could not be traced in Phase 2. Only one of the remaining eight participants is no longer teaching Grade R. All the participants had more than 10 years of teaching experience during Phase 1 and therefore more than 15 years of teaching experience in Phase 2 . In addition, the participants hold qualifications across the ECE phase (birth to 9 years) (Clasquin-Johnson 2011:85;101). Differences between the two phases are reported in the findings and discussions that follow.

\section{Data collection and justification}

Multiple procedures of data collection including interviews, observation and document analysis were employed in Phase 1 (cf Bogdan \& Biklen 2007:59). This enabled the presentation of richly descriptive, detailed data on the nine Grade $R$ teachers (2 teachers at site A, 1 teacher at site B, 1 teacher at site $C$ and 5 teachers at site $D)$. Semi-structured one-on-one interviews informed the research questions and provided detailed insight into participants' beliefs about and perceptions of the official curriculum. The schedule included essential questions, extra questions, throw-away questions and probing questions. The aim was to illuminate participants' understanding of the purpose of the official curriculum and its assessment expectations (ClasquinJohnson 2011:87).

Phase 2 followed 5 years after the initial investigation. I was pleasantly surprised that all the participants remembered me and were as eager to be interviewed as before. I conducted telephonic or face-to-face interviews with the same participants as in Phase 1. The identical in-depth interview protocol was applied as in Phase 1. Regardless of whether the interview was face-to-face or telephonic, the duration was the same and the conversations were recorded with participants' permission and transcribed verbatim. I ensured that the telephonic interviews occurred at participants' convenience when they would not be disturbed. The form of the interview was determined by participants' preferences and availability. Although I did not initially plan to do faceto-face interviews, when scheduling the first two participants' interviews, I realised that they wanted me to visit their classrooms and view their physical resources for myself. Subsequently, wherever possible I visited the participants' classrooms if they were able to accommodate my visit. Although I did not visit all teachers' classrooms, statements such as 'I cannot think of anything else that we could possibly need' confirmed that teachers' resources had improved. This enabled me to compare the findings of the two phases to determine if teachers' responses to CAPS were different to their responses to the NCS. As previously stated, I paid special attention to the external factors (professional development, physical resources and instructional support) that influence teachers' responses to curriculum change and therefore focused on these factors in both phases of the study.

The purpose of Phase 2 was to examine whether the passage of time had altered teachers' responses to curriculum change. Researchers such as Ryder, Banner and Homer (2014) have emphasised that the implementation of curriculum change is a complex and gradual process. Similarly, Briant and Doherty (2012:54) have argued that if the process is 'hurried', it results in minimal change in practice. Moreover, teachers need sufficient time to make sense of the requirements, to see clear evidence of the benefits of a new curriculum (Ebbeck \& Chan 2011:461; Rekkor et al. 2013:503) and to mediate policy into classroom practice (Singh-Pillay \& Alant 2015:90). In addition, learning to be proficient at something new not only takes time and effort; it demands continuous follow-up, support and pressure (Park \& Sung 2013:19; Saylor \& Kerkhoff 2014:11).

\section{Data analysis}

My data analysis was recursive and involved sorting, organising and reducing the data. I compared individual participants' responses to the same interview schedule in Phase 1 and Phase 2. My coding scheme was based on my research question 'How do teachers respond to the introduction of the official curriculum at reception year level?' and my conceptual framework. My method of 
analysing the interviews involved Weft Qualitative Data Analysis, a computer program.

\section{Ethical considerations}

During both phases of this study, I remained mindful of the historic marginalisation of ECE in South Africa and the challenges faced by teachers. I therefore approached the participants with respect and humility. I received permission to conduct the study from the Gauteng Department of Education's Research Directorate in 2009 and again in 2015. Thereafter, I applied for and received ethics clearance from the University of Pretoria's Faculty of Education's Ethics Committee for Phase 1 and from the University of South Africa's College of Education's Ethics Committee for Phase 2, prior to commencing data collection. I have been extremely cautious to protect the participants from harm by ensuring their privacy and confidentiality.

\section{Findings}

Without exception, the Grade R teachers in Phase 1 asserted that they adopted and embraced the curriculum change because it had 'raised the profile of Grade R'. In other words, it had confirmed the educational value of Grade $R$ programmes and elevated its status because it became part of the schooling system. This is consistent with Halbert and MacPhail's (2010:34) study on the implementation of the new Physical Education curriculum in Ireland where status was a key motivator for teachers to adopt curriculum change. However, the data of my study revealed a range of responses to curriculum change. Teachers' responses were mostly chaotic, random and inconsistent and, in some cases, even contradictory. Moreover, they expressed reservations about what they were doing. Most significantly, they regarded some aspects of the curriculum as developmentally inappropriate for their learners.

Although the majority of the participants were critical of the new planning requirements and did not regard it as useful, they adopted it only because their instructional leaders, namely their heads of departments and departmental officials, would check their planning files. These participants described the planning requirements as 'far more complex', 'intensive', 'tedious' and 'time consuming'. However, the well-qualified participants at the best resourced site identified significant benefits, including being more organised and systematic. They described in detail how they adapted this requirement to enrich learning and teaching (ClasquinJohnson 2011:103-104).

In Phase 2, most of the inconsistent responses to implementation had disappeared. All the participants were adopting the curriculum change. In addition, lesson planning is far less problematic as CAPS contains year, term and weekly plans. However, teachers noted that daily lesson planning remains time consuming despite samples having been made available to them. Without exception, all the participants noted that CAPS has enhanced their job satisfaction as they know exactly what to teach and when to teach it. Words such as 'logical', 'organised' and 'well structured' were used by all the participants to describe CAPS. (In Phase 1, this was limited to site D.) The majority of the teachers asserted that, for the first time, they know what is required from them and their learners. One teacher described the main difference between the NCS and CAPS in the following manner: 'Now it's so easy. We are all doing exactly the same content as we simply have to follow the detailed plans provided by the department'.

In what follows, I discuss how certain external factors, namely professional development, physical resources and instructional support, influenced teachers' responses to curriculum change.

\section{Professional development}

Professional development usually follows initial teacher training and aims to enhance teachers' ability to apply their knowledge in practice to support children's learning (Postholm 2012:406). To be effective, it should be ongoing (Hardy 2010:73). Moreover, professional development is critical for teachers to assimilate curriculum change (Klieger \& Yakobovitch 2012:77). Applied to Grade R teachers, professional development in South Africa is much broader and includes developing teachers' disciplinary, pedagogical and practical competence (Department of Higher Education and Training 2015) because the majority of Grade $R$ teachers are underqualified. Although qualifications do not necessarily equate to competence, a positive association has been found between professional development and effective classroom practice if accompanied by adequate support (Ebbeck \& Chan 2011:461; Hargreaves 2005; Hooghuis et al. 2014:246; Rekkor et al. 2013:429; Saylor \& Kerkhoff 2014:3). Furthermore, achieving qualified status is an important policy target for ECE teachers. However, some studies sound a contradictory note. Although professional development for Grade $\mathrm{R}$ teachers is strongly linked to professionalising the early childhood field through enhancing teachers' qualifications, studies such as those conducted by Briant and Doherty (2012:61) as well as Shawer (2010:599) view standardised curricula as de-professionalising teaching.

The findings from Phase 1 revealed that none of the participants regarded themselves as unqualified. Several participants noted that professional development programmes failed to accommodate the broad range of Grade R teachers' needs because the programmes followed a 'one-size-fits-all' approach. For example, the fully qualified participants (site D) noted that they had not learned anything new because they were ahead of what the GDE was offering. In addition, all the participants in the study received an attendance certificate instead of a qualification. One of the participants (site A) had not had any training whatsoever on the NCS. Following her appointment, she received the policy document. She recalled how she had to 'figure it out for myself'. Her curriculum planning suggested that she adapted the curriculum change by extracting the skills from the 
assessment standards and focusing exclusively on skill acquisition (Clasquin-Johnson 2011:114,117).

In Phase 2, the participants with qualifications below NQF Level 7 (equivalent to a 4-year-long Bachelors in Education Degree in Foundation Phase Teaching) acknowledged that they are under-qualified in terms of the Minimum Requirements for Teacher Education Qualifications (MRTEQ) (DHET 2015). These participants expressed frustration that the minimum qualification has increased from NQF Level 5 to Level 7, making qualified status an elusive ideal. This mirrors international trends in early childhood teacher development, which has resulted in very limited understanding of early development and the most poorly trained teachers working in pre-reception year programmes (Garvis \& Lemon 2015:549). Moreover, all the under-qualified participants referred to the looming deadline of 2019 set by the DHET for all teachers to achieve full qualification status, suggesting that this is a significant concern. One participant noted 'I struggled for years to complete my ECD Level 4 and Level 5 qualifications, now I discover I'm still not qualified. I'm so discouraged'.

Without exception, the participants stated that they would prefer to remain in Grade $R$, revealing that their most outstanding common characteristic of being 'passionate about their work' with young children, so clearly evident in Phase 1 (Clasquin-Johnson 2011:149) has been sustained. This is consistent with Goodman's (2014:771) argument that teachers' 'sense of purpose and passion' is essential to implement curriculum change. Teachers regarded the NCS as 'confusing', 'vague' and 'overloaded' with more than 140 assessment standards for Grade R. In contrast, they regard CAPS as 'well structured' and 'clear' and believe that the requirements are meaningful and implementable. In addition, the participants stressed that they enjoy the relative informal nature of Grade $\mathrm{R}$ teaching, despite it being more formal than when they initially began teaching. Significantly, the participants who said they planned to remain in Grade $\mathrm{R}$ all receive higher remuneration as their departmental stipends are supplemented by their school governing bodies. The single participant (site B) who attained a higher qualification since Phase 1 is now teaching Grade 2. It is worth noting that her Grade R colleagues at this no-fee school also intend to move into Foundation Phase posts and intend to enrol in B Ed Degree programmes. Surprisingly, the other participants who are already enrolled in further education programmes do not plan to pursue Foundation Phase posts. Their stipends are already supplemented by their SGBs and they all have received assurances from their principals that they will be financially compensated for remaining in Grade R. In other words, principals have promised to top-up their stipends so that it is equivalent to a departmental post. In addition, two of the participants' study fees are being paid by their respective SGBs. The participants noted that 'the principal convinced the SGB to support us'. This suggests that principals understand the negative impact of high attrition rates/turnover on learners and the overall quality of the school's Grade R classes. Studies on the effectiveness of individual principals confirm that educational leaders are 'critical levers of change' because they create conditions that support or inhibit change (Ishimaru \& Galloway 2014:93; Lai 2015:70). It should also be noted that site B's inability to equalise remuneration is the main reason for teachers' pursuit of Foundation Phase posts. This is problematic as the majority of qualified and experienced Grade $\mathrm{R}$ teachers are unlikely to remain in Grade $R$ unless their remuneration is equivalent to that of Foundation Phase teachers. As a consequence of high turnover, Grade R learners may continuously be taught by inexperienced and unqualified teachers. This finding is significant and is consistent with van der Berg's et al. (2013) finding that Grade $\mathrm{R}$ further extends the advantage of more affluent schools, which in the South African context implies formerly White schools.

Although a specialist Grade R teaching qualification has been introduced (DHET 2015; Janse van Rensburg 2015:107), uptake may be limited to candidates holding a National Senior Certificate (NSC) with restricted access to 'Admission to a Diploma' and those with Further Education and Training qualifications (such as a Further Education and Training Certificate in ECD, FETC: ECD or National Certificate Vocational in ECD, NC (V)) rather than an NSC. The three participants (sites A and B) who are currently enrolled in further studies have opted for Foundation Phase qualifications as they view the Diploma in Grade R Teaching as limiting.

None of the fully qualified participants have pursued postgraduate qualifications as they believe that they are already adequately qualified, experienced and competent. As in Phase 1, their belief that departmental training is 'not particularly useful' has persisted in Phase 2. In addition, although in their opinion, they do not learn anything new, it still has value as it affirms their knowledge and skills and boosts their confidence in their teaching.

\section{Physical resources}

Physical resources significantly influence participants' job satisfaction and morale. In early childhood settings, significant emphasis is placed on a teacher's ability to use concrete, play-based resources to enhance learning and teaching (Samuelsson \& Carlsson 2008:625). In Phase 1, only one site (site D) had well-designed and well-equipped indoor and outdoor play areas. At the other three sites, outdoor play equipment was the most urgent resource need. These participants stressed that they were unable to meet this requirement and were not ignoring it (Clasquin-Johnson 2011:137). At two of the sites (sites A and C), the only outdoor equipment was damaged, unsafe equipment, and as a result, the teachers had to keep their learners away from these areas. Even where the GDE provided outdoor play apparatus (site B), space was so severely limited that the site did not meet the requirements of the guidelines for registration of ECE centres set by the Department of Social Development of a minimum of $3 \mathrm{~m}^{2}$ of outdoor space per learner. If these Grade $\mathrm{R}$ 
classrooms were located in community-based ECE centres instead of in public primary schools, they would not receive Health Certificates from their respective municipalities.

The much greater emphasis on the indoor learning environment has persisted in Phase 2 although the outdoor learning environment has improved. In addition, there has been an increase in physical resources for Language and Mathematics learning and teaching, rather than for free indoor play. Regardless, in Phase 2 a drastic increase in physical resources is evident. Initially, resources were supplied by the GDE. Over time, this has shifted to an annual ring-fenced budgetary allocation as officials' confidence increased in schools' ability to determine their resource needs.

When asked what their most urgent resource needs were, one of the participants at site A responded 'to be honest, I cannot think of a single thing' and several other participants noted that their Foundation Phase colleagues were extremely envious of their resources. Even at site B (the poorest school), a no-fee school where Grade R learners' annual school fees are just R200, the teachers are very satisfied with their resources, noting that they receive an annual budget to purchase resources and that everything they ask for is readily supplied. However, the resources appeared to be under-utilised as they are in a surprisingly pristine condition. During the entire morning of my visit, the children had no contact with the extensive resources. It was as if they could see it but not touch it. This was more pronounced the following day, when a teacher at site D noted that one of their biggest challenges was that the resources constantly needed to be replaced. At site A, parents are held responsible for damaged equipment and an account for the replacement value is sent home. These findings suggest that the content of professional development programmes should guide teachers to (1) use resources more effectively to enhance learning and teaching, (2) understand the importance of learners being allowed to freely engage with the available resources and (3) accept that breakages will inevitably occur.

\section{Instructional support}

In this study, instructional support focused on the role of heads of departments, colleagues and departmental officials who guide, mentor and coach Grade $\mathrm{R}$ teachers on how to implement the curriculum.

In Phase 1, the participants at three of the four sites (sites A, $\mathrm{B}$ and $\mathrm{C}$ ) ignored the requirement to plan their lessons collaboratively. As a result, meaningful collegial support was limited. One participant noted 'my HoD is never satisfied with my planning. I keep doing it over and over and she keeps saying that it's wrong ... I'm convinced she doesn't understand anything about Grade $\mathrm{R}^{\prime}$. At the remaining site (site D), the participants used a team approach to planning which enabled collegial collaboration. What was most significant about their approach was their collective focus on progression, time allocation for each learning programme, articulation between activities and the specific themes as well as curriculum differentiation (Clasquin-Johnson 2011:102).

In Phase 2, all the participants have adopted collegial support, though this was slow and gradual. A marked improvement is that the Grade $\mathrm{R}$ teachers at all four sites are planning their daily lessons within a community of practice. None of the participants is working in isolation as was evident during Phase 1. One participant stated 'every Thursday, we have a Foundation Phase Curriculum Planning meeting to plan for the next week. Our Foundation Phase colleagues now understand what Grade R is all about'. As a consequence, the participants reported that they are enjoying greater job satisfaction. Working in such a collegial manner has enabled the participants to share ideas and strengthen their professional practice and curriculum implementation. This is consistent with the views expressed in international studies that communities of practice encourage professional learning and improve the quality of learning for learners (Halbert \& MacPhail 2010:37; Hardy 2010:72-73; Pausigere \& Graven 2014:34; Taylor 2015:150).

The Gauteng Department of Education's (GDE) involvement in policy implementation and the provision of support and monitoring increased significantly at the end of Phase 1. At the beginning of 2009, none of the participants' classrooms had ever been visited by departmental officials. By the middle of the year, all sites had been informed of specific dates when they would be visited. During the first visit to site A, the participants were following the NCS to a very limited extent, one asserted 'my classroom is my private space' and another admitted 'I'm doing my own thing'. By the time of the third visit, the site had been informed that it would be receiving GDE funding; they were preparing for their first ever official visit and they had begun 'following the NCS much more'. The transition was also witnessed at site D. During the interview with the principal at the end of May 2009, questions were asked pertaining to whether the site had received any learning and teaching support material from the GDE, he noted 'two days ago, I would have said no, but yesterday we received a box of equipment'.

The increased GDE support was accompanied by increased funding as prescribed by the Norms and Standards for Grade R Funding (National Department of Education 2008). Already in Phase 1, several participants noted that they were increasingly adopting the official curriculum. In several instances, this appeared to be limited to formal written planning. Relatively minor aspects seemed to be overemphasised, such as wall displays containing samples of learners' work (Clasquin-Johnson 2011:135).

The GDE's involvement in monitoring policy implementation and the provision of support was non-existent during Phase 1. None of the participants' classrooms had ever been visited by departmental officials. In contrast, in Phase 2 all sites are receiving annual visits to monitor their implementation of 
the curriculum change. I was therefore curious to know what exactly occurs during these visits. Some participants (sites A and D) noted that officials focused on (1) the indoor learning environment, (2) teachers' lesson planning files and (3) learners' assessment portfolios. One participant stressed 'our district official for Grade $\mathrm{R}$ is amazing. We've learnt so much from her. We don't know how we ever managed without her'. In contrast, at one site (site B) the participants reported that if their classroom environment was judged as satisfactory, nothing else would be checked. This was the same site where the learning and teaching support material (LTSM) appeared unused and on display.

\section{Discussion}

As Phase 1 reached its conclusion, a new curriculum was looming on the horizon. Phase 1 revealed that none of the participants were resisting curriculum change. The most highly qualified participants adapted the curriculum to combine play with more formal academic activities to prepare their learners to read and write in Grade One. In Phase 2, it is evident that these teachers are not adopting and adapting the official curriculum as I had previously assumed. Instead, they are adapting their historical best practice to accommodate the requirements of the official curriculum. This is consistent with Vaughn's (2015:44) argument that if implemented appropriately, adaptive teaching is associated with thoughtful, meaningful instruction that accommodates learners' needs. In addition, these teachers are actively involved in 'curriculum making' and innovation, they are continuously reflecting on their evolving lesson planning and consequently they possess a strong sense of curriculum ownership (Catling 2013:431,449; Kesküla et al. 2012:364). According to Lambert and Biddulph (2015:215), this constitutes a 'sophisticated form of curriculum thinking'.

In Phase 1, I argued that teachers with limited knowledge and skills would be more inclined to adopt the official curriculum and to follow it as a script. I did not see evidence of this, mainly because the curriculum (the NCS) was vague. However, one of the main improvements of the CAPS curriculum is that teachers reported that they now know exactly what to teach (content) and when to teach it. Moreover, the teachers in this study regard CAPS as well structured and meaningful.

In Phase 2, the under-qualified teachers appear to be following the curriculum as a script. The participant at site A stated that she and her Grade R colleague followed it 'exactly'. At site B, a typical response to questions posed was 'It's a requirement of CAPS'. One of the participants there noted, 'CAPS says the children must play outside for a whole hour now' (yet her body language strongly suggested that she disagreed), revealing a limited understanding of the educational value of outdoor play. This is consistent with the conceptual framework matrix that positions teachers with low knowledge, low skills and a positive attitude towards change as technicians who are the most likely to adopt curriculum change (Clasquin-Johnson 2011:68).
Similarly, Shawer (2010:599) contends that the developers of scripted curricula view teachers as consumers who passively deliver knowledge, thereby limiting their professional competence. The findings of two Korean studies extend our thinking further. Instead of embracing increased autonomy when encouraged to adapt the curriculum, many teachers resisted either because they lacked the capacity or because it would increase their workload (Hong \& Youngs 2016:31; Park \& Sung 2013:17).

On the whole, the participants appear to be adopting the curriculum change as a result of ongoing monitoring and support, as well as improved resources. The implementation of professional development remains the greatest challenge as it takes a much longer time to provide. Higher education institutions should address these needs as they develop their new qualifications. In addition, recommendations are included for strengthening support and using resources more effectively to enhance learning. This reinforces the findings of Pryor et al. (2012:410-411) in their six country African study that strategies to improve the quality of primary education in sub-Saharan Africa have focused primarily on infrastructure (learning materials, equipment and classrooms) rather than the supply of adequate numbers of teachers or their continuous professional development.

Although the majority of teachers in this study are committed to remaining in their existing Grade $\mathrm{R}$ positions, they are relying on their principals to equalise their remuneration. One unintended consequence is that the best resourced schools will retain their experienced and skilled teachers, whereas poor schools will continuously loose capacity to the Foundation Phase. It further appears that the majority of teachers may pursue departmental posts in the Foundation Phase unless their conditions of service are equalised, hampering the capacity of Grade R classes. The Department of Education is urged to consider the impact of the high turnover of Grade $\mathrm{R}$ teachers on the quality of Grade $\mathrm{R}$ teaching and learning.

\section{Conclusion}

Based on the findings of the two-phase research project described above, I conclude that professional development, physical resources and instructional support should be viewed holistically rather than as separate components. The quality of Grade $\mathrm{R}$ could be enhanced by providing instructional support within communities of practice, where the focus is on social learning, meaningful collaboration and reflection. This would constitute workplace learning and professional development.

The findings further lead to the following recommendations:

- When introducing a new curriculum, teachers should be given sufficient time to make sense of the changes.

- Instructional support is most effective when the head of department is actively involved in a school-based community of practice with colleagues. 
- Departmental officials could enhance curriculum implementation by providing meaningful feedback and advice on teachers' planning and classroom practice.

- Provincial Departments of Education should consider providing all schools offering Grade $\mathrm{R}$ with an annual budgetary allocation for physical resources.

- Professional development opportunities for Grade $\mathrm{R}$ teachers should take into consideration that many teachers want to further their studies and remain in Grade R. Policy-makers should reconsider the career pathway into the Foundation Phase as the only progression option for Grade R teachers. The Departments of Basic Education and Higher Education and Training should assist all Provincial Departments of Education to retain Grade $\mathrm{R}$ teachers by employing them on an equitable basis when compared to other teachers. The remuneration of Grade $\mathrm{R}$ teachers should not depend on the goodwill of principals or a school's ability to equalise salaries.

\section{Acknowledgements}

The author would like to acknowledge feedback and comments received from Proff. Hasina Ebrahim and Billy Fraser during the creation of this article.

\section{Competing interests}

The author declares that she has no financial or personal relationships which may have inappropriately influenced her in writing this article.

\section{References}

Atmore, E., 2013, 'Early Childhood Education in South Africa - Progress since the end of Aparthied', International Journal of Early Years Education 21(2-3), 152-162. http://dx.doi.org/10.1080/09669760.2013.832941

Aubrey, C. \& Durmaz, D., 2012, 'Policy-to-practice contexts for early childhood mathematics in England', International Journal of Early Years Education 20(1), 59-77. http://dx.doi.org/10.1080/09669760.2012.664475

Ballet, K. \& Kelchtermans, G., 2008, 'Workload and willingness to change: Disentangling the experience of intensification', Journal of Curriculum Studies 40(1), 47-67. http://dx.doi.org/10.1080/00220270701516463

Bell, L. \& Stevenson, H., 2005, Education policy: Process, themes and impact, Routledge, London.

Bogdan, R.C. \& Biklen, S.K., 2007, Qualitative research for education: An introduction to theories and methods, 5th edn., Pearson Education, Boston, MA

Brew, A. \& Cahir, J., 2014, 'Achieving sustainability in learning and teaching initiatives', International Journal for Academic Development 19(4), 341-352. http://dx.doi.org/ 10.1080/1360144X.2013.848360

Briant, E. \& Doherty, C., 2012, 'Teacher educators mediating curricular reform: Anticipating the Australian curriculum', Teaching Education 23(1), 51-69. http:// dx.doi.org/10.1080/10476210.2011.620605

Brundrett, M. \& Duncan, D., 2014, 'Leading curriculum innovation in primary schools project: A final report', Education 3-13: International Journal of Primary, Elementary and Early Years Education 1-11. http://dx.doi.org/10.1080/03004279. 2014.975408

Burgess, J., Robertson, G. \& Patterson, C., 2010, 'Curriculum implementation: Decisions of early childhood teachers', Australian Journal of Early Childhood 35(3), 51-60.

Burns, R.W., Yendol-Hoppey, D. \& Jacobs, J., 2015, 'High-quality teaching requires collaboration: How partnerships can create a true continuum of professional learning for educators', The Educational Forum 79, 53-67. http://dx.doi.org/10. 1080/00131725.2014.971990

Catling, S., 2013, 'Teachers' perspectives on curriculum making in Primary Geography in England', The Curriculum Journal 24(3), 427-453. http://dx.doi.org/10.1080/09 585176.2013.801781

Clasquin-Johnson, M.G., 2011, 'Responses of early childhood teachers to curriculum change in South Africa', Unpublished PhD Thesis, University of Pretoria, Pretoria.
Creswell, J.W., 2003, Research design: Qualitative, quantitative and mixed methods approaches, 2nd edn., Sage Publications, Inc, Thousand Oaks, CA.

Creswell, J.W., 2007, Qualitative inquiry and research design: Choosing among five approaches, 2nd edn., Sage Publications, Inc, Thousand Oaks, CA.

Crump, S., 2005, Changing times in the classroom: Teaching as a 'crowded profession', viewed 19 July 2006, from http://www.det.nsw.edu.au/revies/schoolaandr.html

Darling-Hammond, L., 2005, 'Policy and change: Getting beyond bureaucracy', in A. Hargreaves (ed.), The international handbook of educational change, Springer, Dordrecht, The Netherlands.

Ebbeck, M. \& Chan, Y.Y.Y., 2011, 'Instituting change in Early Childhood Education: Recent developments in Singapore', Early Childhood Education Journal 38, 457-463. $\mathrm{http}: / / \mathrm{dx}$.doi.org/10.1007/s10643-010-0435-8

Ebrahim, H., 2010, 'Tracing historical shifts in early care and education in South Africa', Journal of Education 48, 1-17.

Garvis, S. \& Lemon, N., 2015, 'Enhancing the Australian early childhood teacher education curriculum about very young children', Early Child Development and Care 185(4), 549-563. http://dx.doi.org/10.1080/03004430.2014.939652

Goodson, I., 2014, 'Context, curriculum and professional knowledge', Journal of the History of Education Society 43(6), 768-776. http://dx.doi.org/10.1080/004676 0X.2014.943813

Halbert, J. \& MacPhail, A., 2010, 'Curriculum dissemination and implementation in Ireland: Principal and teacher insight', Irish Educational Studies 29(1), 25-40. http://dx.doi.org/10.1080/03323310903522677

Hardy, I., 2010, 'Critiquing teacher professional development: Teacher learning within the field of teachers' work', Critical Studies in Education 51(1), 71-84. http:// dx.doi.org/10.1080/17508480903450232

Hargreaves, A., 2005, 'Introduction: Pushing the boundaries of educational change', in The international handbook of educational change, pp. 1-14, Springer, Dordrecht, The Netherlands.

Haug, K.H. \& Storø, J., 2015, 'Kindergarten - A universal right for children in Norway', International Journal of Child Care and Education Policy 7(2), 1-13. http://dx.doi. org/10.1007/2288-6729-7-2-1

Hoadley, U., 2013, Organising knowledge for the classroom, SAIDE/Oxford University Press, Johannesburg.

Hökkä, P. \& Vähäsantanen, K., 2014, 'Agency-centred coupling - A better way to manage an educational organization?' International Journal on Leadership in Education 17(2), 131-153. http://dx.doi.org/10.1080/13603124.2013.783932

Hong, W. \& Youngs, P., 2016, 'Why are teachers afraid of curricular autonomy? Contradictory effects of the new national curriculum in South Korea', Asia Pacific Journal of Education 36(Suppl. 1), 20-33. http://dx.doi.org/10.1080/02188791.20 14.959471

Hooghuis, F., Van der Schee, J., Van der Velde, M., Imants, J. \& Volman, M., 2014, 'The adoption of thinking through geography strategies and their impact on teaching geographical reasoning in Dutch secondary schools', International Research in Geographical and Environmental Education 23(3), 242-258. http://dx.doi.org/10. 1080/10382046.2014.927168

Ishimaru, A.M. \& Galloway, M.K., 2014, 'Beyond individual effectiveness: Conceptualizing organizational leadership for equity', Leadership and Policy in Schools 13(1), 93-146. http://dx.doi.org/10.1080/15700763.2014.890733

Janse van Rensburg, O., 2015, 'The school readiness performance of a group of Grade $\mathrm{R}$ learners in primary schools in the Gauteng Province of South Africa', South African Journal of Childhood Education 5(1), 106-124. http://dx.doi.org/10.4102/ sajce.v5i1.352

Kesküla, E., Loogma, K., Kolka, P. \& Sau-Ek, K., 2012, 'Curriculum change in teachers' experience: The social innovation perspective', Pedagogy, Culture \& Society 20(3), 353-376. http://dx.doi.org/10.1080/14681366.2012.712051

Klieger, A. \& Yakobovitch, A., 2012, 'Contribution of professional development to standards implementation', Teacher Development 16(1), 77-88. http://dx.doi.org St10.1080/13664530.2012.674290

Lai, E., 2015, 'Enacting principal leadership: Exploiting situated possibilities to build school capacity for change', Research Papers in Education 30(1), 70-94. http:// dx.doi.org/10.1080/02671522.2014.880939

Lambert, D. \& Biddulph, M., 2015, 'The dialogic space offered by curriculum-making in the process of learning to teach, and the creation of a progressive knowledgeled curriculum', Asia-Pacific Journal of Teacher Education 43(3), 210-224. http:// dx.doi.org/10.1080/1359866X.2014.934197

Leander, K.M. \& Osborne, M.D., 2008, 'Complex position: Teachers as agents of curricular and pedagogical reform', Journal of Curriculum Studies 40(1), 23-46. http://dx.doi.org/10.1080/00220270601089199

Lindblad, S., 1990, 'From technology to craft: On teachers' experimental adoption of technology as a new subject in the Swedish primary school', Journal of Curriculum Studies 22(2), 165-175. http://dx.doi.org/10.1080/0022027900220205

Lingarda, B., Martinob, W. \& Rezai-Rashtib, G., 2013, 'Testing regimes, accountabilities and education policy: Commensurate global and national developments', Journal of Education Policy 28(5), 539-556. http://dx.doi.org/10.1080/02680939.2013.82 0042

Liyanage, I., Bartlett, B., Walker, T. \& Guo, X., 2015, 'Assessment policies, curricular directives, and teacher agency: Quandaries of EFL teachers in Inner Mongolia', Innovation in Language Learning and Teaching 9(3), 251-264. http://dx.doi.org/1 $0.1080 / 17501229.2014 .915846$

Logan, H., Sumsion, J. \& Press, F., 2015, 'The Council of Australian Government Reforms (2007-2013): A critical juncture in Australian Early Childhood Education and Care (ECEC) policy?', International Journal of Child Care and Education Policy 9(1), 1-16. http://dx.doi.org/10.1186/s40723-015-0011-1 
Lowrie, T., 2014, 'An educational practices framework: The potential for empowerment of the teaching profession', Journal of Education for Teaching 40(1), 34-46. http:// dx.doi.org/10.1080/02607476.2013.86401.6

MacLean, J., Mulholland, R., Gray, S. \& Horrell, A., 2015, 'Enabling curriculum change in Physical Education: The interplay between policy constructors and practitioners' Physical Education and Sport Pedagogy 20(1), 79-96. http://dx.doi.org/10.1080/ 17408989.2013.798406

Merekua, D.K. \& Merekub, C.W.K., 2015, 'Congruence between the intended implemented, and attained ICT curricula in Sub-Saharan Africa', Canadian Journal of Science, Mathematics and Technology Education 15(1), 20-34. http://dx.doi.org/ 10.1080/14926156.2014.992555

National Department of Education, 2008, Norms and standards for Grade $R$ funding Government Gazette No. 30679, Government Printer, Pretoria.

Park, M. \& Sung, Y., 2013, 'Teachers' perceptions of the recent curriculum reforms and their implementation: What can we learn from the case of Korean elementary teachers?', Asia Pacific Journal of Education 33(1), 15-33. http://dx.doi.org/10.10 80/02188791.2012.756391

Pausigere, P. \& Graven, M., 2014, 'Learning metaphors and learning stories (stelos) of teachers participating in an in-service numeracy community of practice', Education as Change 18(1), 33-46. http://dx.doi.org/10.1080/16823206.2013.847027

Philippou, S., Kontovourki, S. \& Theodorou, E., 2014, 'Can autonomy be imposed? Examining teacher (re)positioning during the ongoing curriculum change', Cyprus Journal of Curriculum Studies 46(5), 611-633. http://dx.doi.org/10.1080/002202 72.2013.856033

Pinar, W.F., 1999, 'Not burdens: Breakthroughs', Curriculum Inquiry 29(3), 365-367. http://dx.doi.org/10.1111/0362-6784.00133

Postholm, M.B., 2012, 'Teachers' professional development: A theoretical review', Educational Research 54(4), 405-429. http://dx.doi.org/10.1080/00131881.2012. 734725

Pryor, J., Akyeampong, K., Westbrook, J. \& Lussier, K., 2012, 'Rethinking teacher preparation and professional development in Africa: An analysis of the curriculum of teacher education in the teaching of early reading and mathematics', The Curriculum Journal 23(4), 409-502. http://dx.doi.org/10.1080/09585176.2012.74 7725

Qiana, H. \& Walker, A., 2013, 'How principals promote and understand teache development under curriculum reform in China', Asia-Pacific Journal of Teacher Education 41(3), 304-315. http://dx.doi.org/10.1080/1359866X.2013.809050

Rekkor, S., Ümarik, M. \& Loogma, K., 2013, 'Adoption of national curricula by vocational teachers in Estonia', Journal of Vocational Education and Training 65(4), 489-506. http://dx.doi.org/10.1080/13636820.2013.841277

Richardson, V. \& Placier, P., 2002, Handbook of research on teaching, 4th Edn., American Educational Research Association, Washington, DC.

Rowan, B. \& Miller, R., 2007, Organizational strategies for promoting instructional change: Implementation dynamics in schools working with comprehensive school reform providers', American Educational Research Journal 44(2), 252-297. http:// dx.doi.org/10.3102/0002831207302498

Ryder, J., 2015, 'Being professional: Accountability and authority in teachers' responses to science curriculum reform', Studies in Science Education 51(1), 87-120. http://dx.doi.org/10.1080/03057267.2014.1001629
Ryder, J., Banner, I. \& Homer, M.S., 2014, 'Teachers' experiences of science curriculum reform', School Science Review 95(352), 126-130. ISSN 0036-6811.

Samuelsson, I.P. \& Carlsson, M.A., 2008, 'The playing learning child: Towards a pedagogy of early childhood', Scandinavian Journal of Educational Research 52(6), 623-641. http://dx.doi.org/10.1080/00313830802497265

Savage, G.C., O'Connor, K. \& Brass, J., 2014, 'Perspectives: Common Core State Standards: Implications for Curriculum, Equality and Policy', Journal of Curriculum and Pedagogy 11, 18-49. http://dx.doi.org/10.1080/15505170.2014.908436

Saylor, E.E. \& Kerkhoff, S.N., 2014, 'Change is the only constant: Beginning teacher perceptions of implementing the common core state standards', Current Issues in Education 17(3), 1-20

Shawer, S., 2010, 'Classroom-level teacher professional development and satisfaction: Teachers learn in the context of classroom-level curriculum development' Professional Development in Education 36(4), 597-620. http://dx.doi.org/10.1080/ 19415257.2010.489802

Singh-Pillay, A. \& Alant, B., 2015, 'Tracing the policy mediation process in the implementation of a change in the Life Sciences curriculum', African Journal of
Research in Mathematics, Science and Technology Education 19(1), 12-22. http:// dx.doi.org/10.1080/10288457.2014.1002297

Smylie, M.A. \& Perry, G.S., 2005, 'Restructuring schools for improved teaching', in A Hargreaves (ed.), The international handbook of educational change, pp. 306335, Springer, Dordrecht, The Netherlands.

South Africa, Department of Education, 2001, National Policy Act, 1996 (Act No. 27 of 1996). Education White Paper 5 on Early Childhood Education: Meeting the challenge of early childhood development in South Africa, Government Gazette 22938, Notice 1369, (13 December 2001).

South Africa, Department of Higher Education and Training (DHET), 2015, National Qualifications Framework Act 67 of 2008: Policy on Minimum Requirements for Teacher Education Qualifications, Government Gazette 34467, Notice 583 (15 July 2011).

Taylor, P., 2015, 'Communities of practice: Identity in a workplace English for specific purposes classroom in Thailand', International Journal of Continuing Education and Lifelong Learning 7(2), 149-169.

Van der Berg, S., Girdwood, E., Shepherd, D., van Wyk, C., Kruger, J., Viljoen, J. et al., 2013, The impact of the introduction of Grade R on learning outcome: Final Report (Policy Summary, Executive Summary \& Evaluation Report) for the Department of Basic Education and the Department of Performance Monitoring and Evaluation in the Presidency 17 June 2013, Research on socio-economic policy (ReSEP) Department of Economics, University of Stellenbosch, Stellenbosch.

Vaughn, M., 2015, 'Adaptive teaching: Reflective practice of two elementary teachers' visions and adaptations during literacy instruction', Reflective Practice 16(1), 43-60. http://dx.doi.org/10.1080/14623943.2014.944143

Webster, J. \& Watson, R.T., 2002, 'Analysing the past to prepare for the future: Writing a literature review', MIS Quarterly 26(2), xiii-xxiii.

Wiersma, W. \& Jurs, S.G., 2009, Research methods in education: An introduction, 9th edn., Pearson/Allyn and Bacon, Philadelphia, PA.

Zhu, J., 2015, 'Early Childhood Education and relative policies in China. Internationa Journal of Child Care and Education Policy 3(1):51-60. http://dx.doi. org/10.1007/2288-6729-3-1-51 